\title{
Influence of differential heat treatment on foodstuffs with apples obtained by the convection-thermoradiation method of drying
}

\author{
Liudmila Strelchenko, Igor Dubkovetskyi, Ivan Malezhyk
}

\author{
National University of food Technologies, Kyiv, Ukraine
}

Keywords:
Apple
Snack
Candied fruit
Blanching
Drying

Article history:

Received

11.09.2018

Received in

revised form

09.01.2019

Accepted

28.03.2019

\section{Corresponding author:}

Igor Dubkovetskyi

E-mail:

dubkov78@ukr.net

DOI:

10.24263/2304974X-2019-8-1-15

\section{Abstract}

Introduction. The influence of differential heat treatment on products from apples with different sugar content in semi-finished products is considered.

Materials and methods. Material for drying elect apples varieties «Golden Delicious». Samples of dried apples, snack and candied fruits were analyzed by organoleptic, physico-chemical and differential-thermal effects. The prepared semi-finished products were dried by the convective-thermoradiational method at a coolant temperature of $60^{\circ} \mathrm{C}$, a coolant movement speed of $5.5 \mathrm{~m} / \mathrm{s}$, a specific load of $8.8 \mathrm{~kg} / \mathrm{m}^{2}$, an exposure value of thermal radiation heating elements of $8 \mathrm{~kW} / \mathrm{m}^{2}$, and an external heating element power of 2.5 $\mathrm{kW} / \mathrm{m}^{2}$.

The results and discussions. Based on the drying curves, the rate of moisture removal occurred in direct proportion to the increase in the concentration of sugar in the products. Drying time of products depends on the content of dry substances (DM) in semi-finished products: which were $12 \%$ for dried apples, $18.2 \%$ for snack and $72 \%$ for candied fruits. Energy costs for dried apples, snack and candied fruits are respectively $5.9 ; 7.55 ; 19.8 \mathrm{~kW}$ in $\mathrm{kg}$ of raw materials and $1.93 ; 1.99 ; 26.0 \mathrm{MJ} / \mathrm{kg}$ of evaporated moisture. The dependence is observed, the greater the concentration of sugar in the semi-finished product, the longer it takes to remove moisture from the material.

In the presented derivatograms, when apples were heated in the $\mathrm{T}_{1}=108^{\circ} \mathrm{C}$ region, a mass loss of $\Delta \mathrm{m}=13.0 \%$ was observed, which was accompanied by an endothermic peak on the DTA dependence. This mass loss is due to evaporation of moisture. When the temperature increased to $\mathrm{T}_{2}=140^{\circ} \mathrm{C}$, destruction began to occur in the sample. When the snack was heated at $\mathrm{T}_{1}=108^{\circ} \mathrm{C}$, the mass was lost by $\Delta \mathrm{m}=14.5 \%$, which was accompanied by an endothermic peak on the DTA dependence. As the temperature rises to $\mathrm{T}_{2}=131{ }^{\circ} \mathrm{C}$, destruction begins to occur in the sample. Heating the candied fruit at $\mathrm{T}_{1}=109{ }^{\circ} \mathrm{C}$ resulted in a weight loss of $\Delta \mathrm{m}=14.8 \%$ with an endothermic peak on the DTA dependence. As the temperature rises to $\mathrm{T}_{2}=125^{\circ} \mathrm{C}$, destruction begins to occur in the sample.

Conclusions. Based on the derivatogram (T, TG, DTG, and DTA time dependencies), the prediction factor $\left(\mathrm{k}_{0}\right)$ was calculated for dried apples, snack and candied fruits to be $55 ; 61 ; 70$ and also activation energy (E) for dried apples, snacks and candied fruits, respectively, 186; 203 and $236 \mathrm{~kJ} / \mathrm{mol}$. 


\section{Introduction}

Based on the literature analysis, it becomes clear that a certain part of scientists is focused on finding a way to dry apple snack, a selection of technological parameters and process decisions that will have a significant impact on the quality of the finished product, and another part on the pretreatment of apple raw materials, which to some extent affects on the structural, organoleptic and physico-chemical properties of the finished product.

Preparation of apple raw materials is crucial for obtaining high-quality apple snack, because it depends on the chemical composition and nutritional value of the product.

Since 2004, studies have been conducted on the processing of raw apple material by blanching in a sugar, maltose syrup [1,2]; immersion in a solution of $\mathrm{CaCl}_{2}$ and citric acid [3]; blanching with citric acid solution [4]; treatment with a solution of ascorbic acid [5] and enrichment of apple particles with probiotics [6]. However, there are a number of problems that need to be addressed. Blanching in sugar or maltose syrup affects only the taste of the finished product; osmotic processing of raw materials in $\mathrm{CaCl}_{2}$ solution with citric acid has several disadvantages, since $\mathrm{CaCl}_{2}$ is a synthetic compound, affects the product's organoleptics by providing a bitter-salty flavor that is not always perceived by the consumer and has limitations for the use of various populations, including children, pregnant women, people with heart disease and high calcium in the blood. Enriching the particles of apples with probiotics can reduce the $\mathrm{pH}$ of the product, which is not always advisable, probiotics should not cause adverse reactions with prolonged use of the product, but special conditions are required for the storage of such a product.

Research problems remain the development of an optimal method of drying, and the creation of a fundamentally new product from apples that will be as close as possible in terms of the chemical composition of the finished product to the chemical composition of the raw material with maximum preservation of vitamin $\mathrm{C}$.

The purpose of this work is the need to create apple snack that will satisfy the consumer's food preferences with pre-processing of raw materials, which focuses on the taste and physico-chemical characteristics of the product without the use of artificial flavors, dyes and preservatives.

The task of the work is to study the effect of pretreatment of apple raw materials on the process of convective-thermoradiational drying and differential thermal analysis of apple snack and their comparison with such foods as dried apples and candied fruits using the example of convective- thermoradiational drying.

\section{Materials and methods}

\section{Investigated materials}

Raw materials that were used in research are autumn and winter sorts of apples «Semerenko», «Lihold», «Champion», «Golden Delicious» and «Reinette» with the high sugar-acid index (more than 8), the high content of the original dry substances (more than $12 \%$ ), large fruit size (more than $200 \mathrm{~g}$ ) and activity of oxidative processes. In order to minimize waste, the ratio of the pulp to the inedible part was taken into account. According to these indicators apples varieties like «Champion» and «Golden Delicious» were chosen, but «Champion» has bigger peroxidase activity, that's why the variety «Golden Delicious» was chosen as the best one. 
Prior preparation for drying apples consisted of washing apples, inspecting, cleaning from inedible parts (skin and seed chamber), cutting into 3-6 mm parts and blanching in hot water with a temperature of 96-100, then cooling and sending to drying. The production of dried apples was carried out according to the patent of Ukraine № 105128 «Method for the production of apple snack».

Preparation for apple candied fruit consisted of cooking jam in 3 stages with the same modes: boiling for 30 minutes, then cooling to room temperature, to let the sugar be absorbed into the fruit and in order to avoid overcooking the fruits of apples. The boiling ended when the dry matter in the syrup reached $78 \%$, in the fruit $70-72 \%$. After that, the fruit was separated from the sugar syrup, washed, cut into pieces of $15 \times 15 \mathrm{~mm}$. After that, they were sent for drying. Production of candied fruits was carried out according to the patent of Ukraine for the invention №. 113569 «Method of production of candied fruits».

Preparation of raw materials in the apple snack production did not differ from the preparation for apple drying apples, but blanching occurred in 30\% sugar syrup, with a ratio of apples and syrup as 1:2 with the addition of citric acid $1 \%$ and ascorbic acid in the amount of $0.01 \%$. Then it was cooled in the same syrup at a temperature of $18-20{ }^{\circ} \mathrm{C}$. Such an operation is necessary in order that the apple pieces do not lose their shape and absorb a portion of sugar with citric acid. Sugar with ascorbic acid forms a protective shell that reduces the access of oxygen during drying, and as a result, the finished product retains the light yellow color common to the used raw material and the vitamin complex [7].The production of apple snack was carried out according to the patent of Ukraine for the invention № 113587 «Method for the production of apple snack».

\section{Procedure of conducting researches}

Prepared semi-finished products were sent for convective-thermoradiational drying. The drying parameters were established experimentally: the coolant temperature in the drying chamber was 60 , the velocity of air in the chamber was $5.5 \mathrm{~m} / \mathrm{s}$; surface allowance -8.8 $\mathrm{kg} / \mathrm{m}^{2}$; the amount of radiation irradiated by thermoradiation heating elements was $8 \mathrm{~kW} / \mathrm{m}^{2}$, the wavelength of tubular «dark» thermoradiation generators was 2.0-4.0 microns; the air was heated from an external heating element of $2.5 \mathrm{~kW} / \mathrm{m}^{2}$; the distance between thermoradiational heaters and the product was $14 \mathrm{~cm}$.

After drying, three samples of apples were obtained: dried apples, snack and candied fruits. In order to objectively evaluate these products, a qualitative and differential thermal analysis was performed.

\section{Methods and research facilities}

\section{Methods of analysis}

The organoleptic analysis was carried out by tasting and comparing dried products using a convective-thermoradiational method with dried convection products.

During physico-chemical analysis of the mass fraction of dry substances was determined by the refractometric method [8]; moisture content - by the accelerated method of Chizhova [22]; the content of organic acids was determined by alkali titration (in terms of malic acid) [10]; sugar content - using the permanganate method [11]; the content of mineral impurities (ash) - the irrigation of a batch weight [12]; the content of pectin substances using calcium pectate [13]; vitamin $\mathrm{C}$ content is potentiated by titration of 2,6dichlorophenolindophenol [14]. 
Differential-thermal analysis of products was performed using a «Paulik-Paulik-Erdey Q-1500 D derivatograph». The method of differential thermal analysis (DTA) is based on a comparison of the properties of a test substance sample and a thermally inert substance accepted as a standard. The recording parameter was the temperature difference measured when the sample was heated or cooled at a constant rate, which can be represented as a change in the sample temperature or standard. A change in the temperature of a sample is caused by physical transitions or chemical reactions associated with changes in enthalpy. These include: phase transitions, melting, boiling. These transformations are accompanied by absorption or release of heat. In the genera, phase transitions are accompanied by endothermic effects, and oxidation and individual decomposition processes - by exothermic effects.

\section{Research equipment}

Convective-thermoradiational drying plant. The research of the drying process of products was carried out on a laboratory convective-thermoradiational drying unit (Figure 1), which was made in accordance with the Ukrainian patent for invention № 112348 «Radiation-convective drying unit».

The drying chamber 1 , is made of polished aluminum, which has a high coefficient of thermal radiation reflection and is 0.86 , which ensures homogeneous irradiation of raw materials during drying. Air is supplied to the chamber by means of the fan blades 2 , passing gradually through the external heater 3 and the drying chamber, in which it contacts with the material, supplying heat to it and at the same time removing moisture from the product. The semi-finished product is formed into a layer on a special grid-stand in a box-shaped mesh basket 5 , which is mounted on an analytical balance 7 through the hole in the bottom wall of the drying unit. Thermoradiational irradiation is performed by emitters 4 .

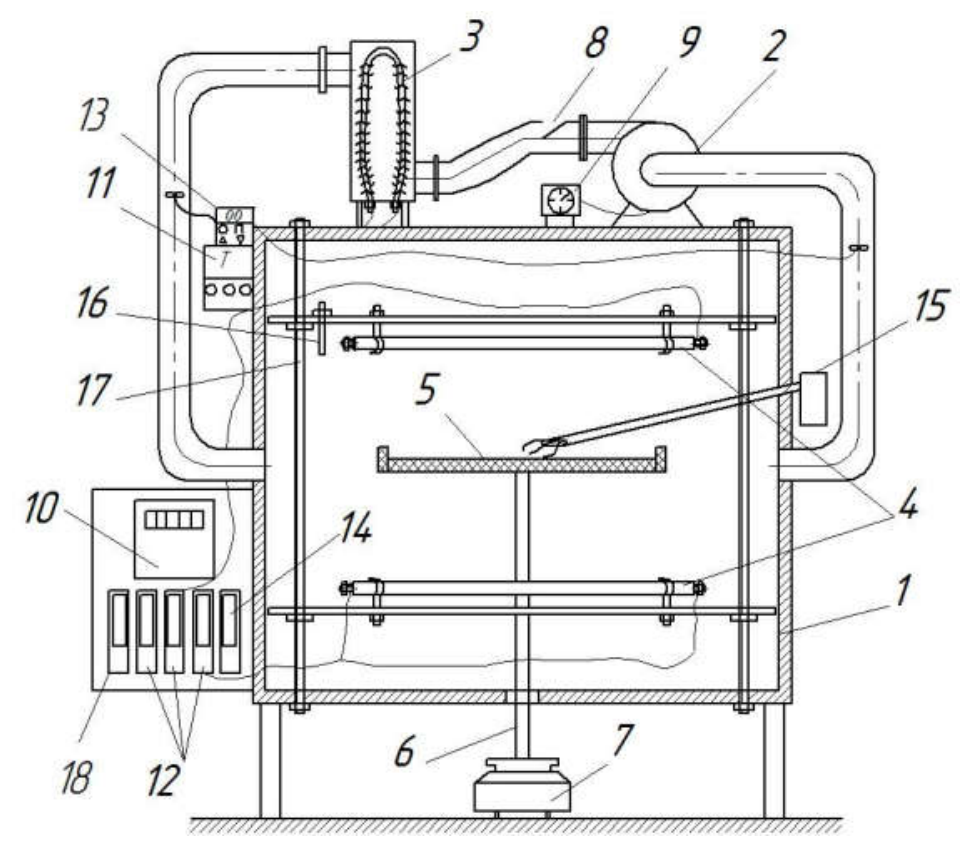

Figure 1. Schematic diagram of a convection-thermal modi-sion drying unit 
With the help of vertical guides 17 , it is possible to change and fix the the nodes position of thermoradiational generators, thus changing the irradiation amount of the samples and the volume of the working chamber. The design of the sample unit of infrared radiators allows the use of «light» and «dark» thermo-radiation generators for drying raw materials. The air heated by the heater is supplied to the drying chamber at a certain speed, the value of which is controlled by the automatic control unit of the heat carrier speed 9 of the electric fan 2 . The registration unit for reducing the mass of drying material, it is a modified design of analytical weights 7 , which are connected by a bar 6 to the mesh basket 5 . Setting the temperature of the coolant is carried out by the automatic temperature control unit 11 with a minimum inaccuracy of 1 . The range of turning on and off heaters characterizes the irradiation time for semi-finished products. Energy consumption per kilogram of finished products or evaporated moisture is carried out using a counter 10. Air recirculation in the dryer was carried out using a gate 8 . The change of air relative humidity on entrance and exit of the drying chamber was recorded using the automatic control unit of relative humidity 13 . Deenergize the heater generators can be done with a help of automatic switches 12 . The temperature change in the cross section of the semi-finished product was recorded with a thermometer with thermocouples 15 . Drying was performed in a pulsed heating-cooling mode. Thermoradiational beams and external convective heating elements provided the heating. After reaching the maximum set temperature for drying, thermoradiational emitters and the external heater were switched to the pulse switching mode. The duration of the impulse and pause correlated as 1:1,1:2,1:3, etc. The temperature was recorded by a contact temperature sensor 16 , the signal of which was supplied to turn the generators on or off to the relay 18 .

Derivatograph «Paulik-Paulik-Erdey Q-1500 D». Differential thermal analysis was performed on a «Paulik-Paulik-Erdey Q-1500 D» system derivatograph.

The derivatograph (Figure 2) consists of crucible 1 with a sample, crucible 2 with a standard, ceramic tube 3 , thermowaight 4 , differential transformer 5 , magnet 6 , coil 7 .

The device can operate in two modes: simple thermometry mode and differential thermometry mode. In the first case, one simple thermocouple is used in the work, on which a crucible with a sample is placed. In the second case, a differential thermocouple is used, consisting of two simple thermocouples connected by the same poles to each other. On one of them was a crucible with a sample, on the other - with a reference substance. One of the shooting modes was chosen using the switch located on the front panel of the device.

On the second balance beam weights placed two devices with which they measured the loss and rate of weight loss of the sample. The principle of operation of these devices is based on the phenomenon of magnetic induction.

A differential transformer consisting of three coils arranged vertically on the same axis was used to measure the mass loss. The transformer is fixed at the instrument case. Inside the transformer is placed a metal core suspended on the balance arm. This core displaces when the mass of the test sample changes. When alternating current is supplied to the middle coil (primary winding of the transformer), an induction current arises in adjacent coils (secondary winding of the transformer) connected to each other (differentially). With a symmetrical arrangement of the core along the coils of the secondary winding of the transformer, the total voltage on them is almost zero (the initial position of the scale). When the core is displaced, the total voltage changes in proportion to the displacement. Thus, the differential transformer converts the movement of the weights arm into an electrical signal, which is recorded by a recording device. The differential transformer is characterized by high sensitivity and measurement accuracy. 


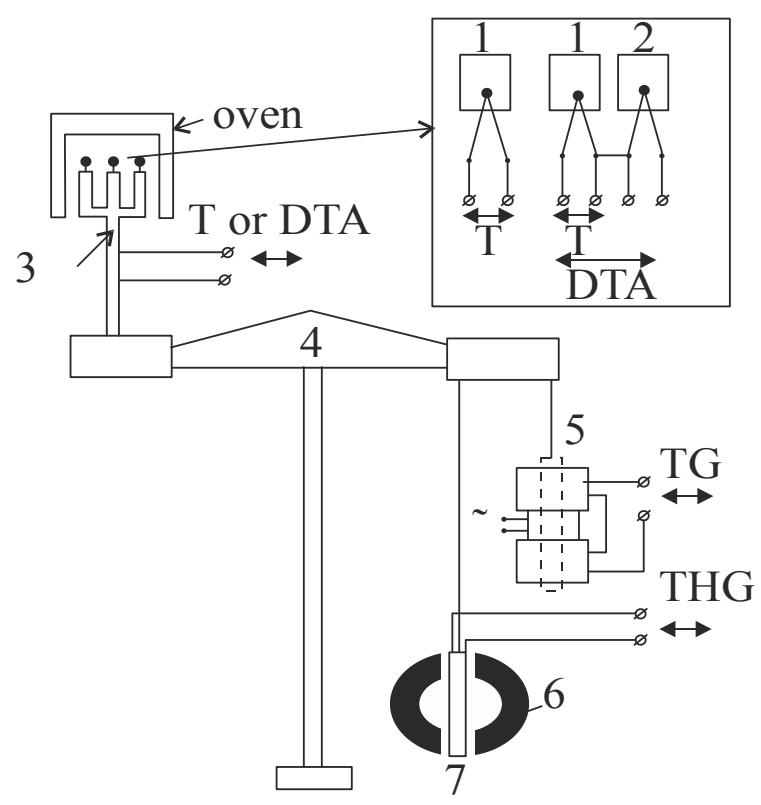

Figure 2. Schematic diagram of the derivatograph

The THG curve is obtained using a device consisting of a permanent magnet and an induction coil. The induction coil is suspended from the scale and placed in a permanent magnet field. When the sample mass changes, the coil begins to move in a homogenous magnetic field. During this movement in the coils occurs induction current, the value of which is proportional to the rate of mass change.

Signals from thermocouples, a differential transformer and an induction coil were fed through an amplifier to a computer monitor and we simultaneously received simple (T) and differential thermal (DTA) analysis curves, a mass loss curve (TG) and a mass loss rate curve (THG).

Methods for calculating the kinetic parameters of the dehydration process, such as the activation energy $(\mathrm{E})$ and the preconference factor $\left(\mathrm{k}_{0}\right)$, are described in [15]. written as:

The kinetic equation of the desorption process in differential thermal analysis can be

$$
\mathrm{d} \Theta / \mathrm{dt}=-\mathrm{k} \Theta^{\mathrm{n}} ; \mathrm{k}=(-\mathrm{d} \Theta / \mathrm{dt}) / \Theta^{\mathrm{n}}
$$

The degree of coating of biopolymer molecules with water $(\Theta)$ varies from 1 - filling for the starting material to 0 - all water is dehydrated. The order of reaction (n) - is an integer from 1 to 3 , it is assumed that it is known from the experiment. Constant rate of reaction

$$
\mathrm{k}=\mathrm{k}_{0} \exp (-\mathrm{E} / \mathrm{RT}) \text {, }
$$

where $\mathrm{R}$ - is the universal gas constant. The value of $\mathrm{E}$ approaches a constant, which means the equivalence of all biopolymer molecule surface hydration centers. Substituting equation (1) into equation (2) and logarithmically we get

$$
\ln \mathrm{k}=\ln \left[(-\mathrm{d} \Theta / \mathrm{dt}) / \Theta^{\mathrm{n}}\right]=\ln \mathrm{k}_{0}-\mathrm{E} / \mathrm{RT}
$$


Bearing in mind the initial conditions $\Theta_{t=0}=1, \Theta_{t=\infty}=0$ and conducting the experiment at a constant heating rate $(\beta)$, that is, the linear dependence of the temperature on time

$$
\mathrm{T}(\mathrm{t})=\mathrm{T}_{0}+\beta \mathrm{t},
$$

the following expressions can be written:

$$
\Theta(t)=S_{T} / S_{0} ;-d \Theta / d t=\beta f_{2} / S_{0},
$$

where $S_{0}$ and $S_{T}-$ are respectively the area on the graph $f_{2}$ under the whole peak and the peak part from $\mathrm{T}$ to $\infty$

$$
\mathrm{S}_{\mathrm{T}}=\int_{\mathrm{T}}^{\infty} f_{2} \mathrm{dT} ; \mathrm{S}_{\mathrm{O}}=\int_{0}^{\infty} f_{2 \mathrm{dT}}
$$

If all the assumptions inherent in this method are correct and the reaction order $\mathrm{n}$ is chosen correctly, then the dependence of $\ln \left[(-\mathrm{d} \Theta / \mathrm{dt}) / \Theta^{\mathrm{n}}\right]$ on the inverse temperature (equation 3 ) is linear over the entire temperature range. Having experimental values of $f_{2}$ and $\beta$, using expressions (5) and (6), we obtain $\Theta$ and $\mathrm{d} \Theta$ / dt parameters of non-isothermal kinetics $\mathrm{k}_{0}$ and $\mathrm{E}$ are calculated from equation (3). The advantage of the above procedure is the use of the entire array of experimental data, including the high-temperature part of the thermogram, which is especially important in determining order $\mathrm{n}$, determining the reaction mechanism and the adequacy of the model.

\section{Result and discussion}

\section{apples \\ Investigation of the kinetics of convective-thermoradiation drying products from}

On the basis of the data obtained, drying curves were constructed (Figure 3), characterizing the change in moisture content of $\mathrm{W}^{\mathrm{c}}$ depending of time $\tau$. The Figure shows that the warm-up period for all samples is minimal, and the rate of moisture removal was directly proportional to the increase in the concentration of sugar in the products.

Analyzing Figure 3, it can be said that the heating period for all samples of semi-finished products is minimal (about 2-3 minutes), and then there is a rapid period of moisture removal ( $3 a$ ). From Figure $3 b$ it can be seen that the process of removing moisture in the second period is long, since the sugar concentration is high and moisture in the intermediate contains osmotic bonds, which significantly complicates the drying process [19].

Approximating the data of the first and second drying periods, we derived the equation of the moisture content of $\mathrm{W}^{\mathrm{c}}$ from the drying time $\tau$ (Table 1).

After drying, samples of finished products for which a physico-chemical analysis was performed (Table 2) were obtained. 

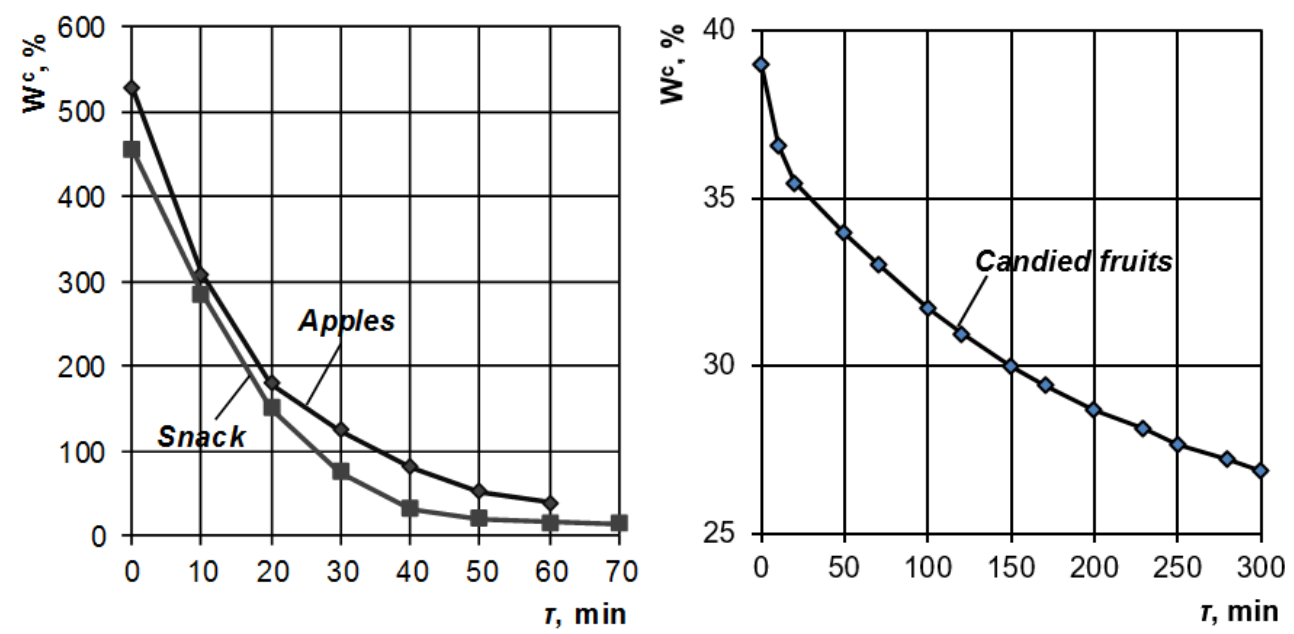

Figure 3. Drying curves of apples:

$a$ - apples and snack; $b$ - candied fruits

Equation of moisture content $\mathrm{W}^{\mathrm{c}}(\%)$ from the drying time $\tau(\mathrm{min})$

Table 1

\begin{tabular}{|l|c|c|}
\hline \multicolumn{1}{|c|}{ Product } & 1 period & 2 period \\
\hline Dried apples & $\begin{array}{c}W^{c}=-22,06 \tau+527,45 \\
\text { at } R^{2}=0,99\end{array}$ & $\begin{array}{c}W^{c}=4941,8 \tau^{-1,137} \\
\text { at } R^{2}=0,95\end{array}$ \\
\hline Snack & $\begin{array}{c}W^{c}=-17,544 \tau+452,56 \\
\text { at } R^{2}=0,99\end{array}$ & $\begin{array}{c}W^{c}=3418,2 \tau^{-1,07} \\
\text { at } R^{2}=0,99\end{array}$ \\
\hline Candied fruits & $\begin{array}{c}W^{c}=-0,213 \tau+32,04 \\
\text { at } R^{2}=1\end{array}$ & $\begin{array}{c}W^{c}=55,57 \tau^{-0,26} \\
\text { at } R^{2}=0,99\end{array}$ \\
\hline
\end{tabular}

Physico-chemical analysis for apple products

Table 2

\begin{tabular}{|c|c|c|c|}
\hline \multirow[t]{2}{*}{ Indicator } & \multicolumn{3}{|c|}{ Product } \\
\hline & Dried apples & Snack & Candied fruits \\
\hline Dry matter of fresh apples, $\%$ & \multicolumn{3}{|c|}{12,0} \\
\hline Dry substances of apples, $\%$. & 87 & 84,5 & 85,2 \\
\hline Mono- and bi-sugars, \%. & 61,5 & 63 & 76,1 \\
\hline Organic acids, $\%$ & 2,4 & 2,3 & 1,5 \\
\hline Pectin substances, $\%$. & 4,9 & 4,4 & 0,8 \\
\hline Dietary fiber, $\%$. & 4,3 & 4,3 & 4,2 \\
\hline Mineral substances, $\%$. & 2,7 & 2,6 & 0,7 \\
\hline Vitamin $\mathrm{C}, \mathrm{mg} \%$ & 4,6 & 8,3 & 6,8 \\
\hline
\end{tabular}


When processing the drying process data, the energy consumption for all product samples in $\mathrm{kWh}$ in $\mathrm{kg}$ of raw materials (Figure 4 a) and in $\mathrm{MJ} / \mathrm{kg}$ of evaporated moisture (Figure 4 b) was obtained.
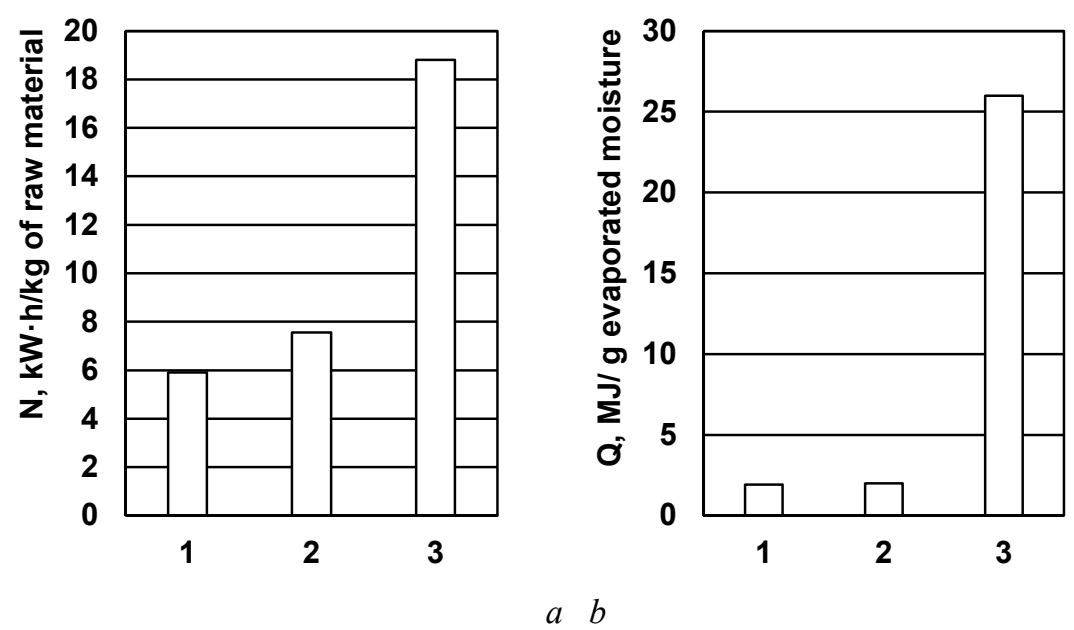

Figure 4. Electricity consumption per $1 \mathrm{~kg}$ of raw materials $(4 \mathrm{a})$ and $1 \mathrm{~kg}$ of evaporated moisture $(4 \mathrm{~b})$ for apple products: 1 - dried apples; 2 - snack; 3 - candied fruits

In Figure 4, the dependence is observed, the greater the concentration of sugar in the semi-finished product, the longer it takes to remove moisture from the material.

\section{Study of differential thermal analysis of products from apples}

Figure 5, Figure 6 and Figure 7 show tree patterns (time dependences of T, TG, DTG, and DTA) for the product samples.

When the apples were heated at $\mathrm{T}_{1}=108{ }^{\circ} \mathrm{C}$, the mass was lost by $\Delta \mathrm{m}=13.0 \%$, which was accompanied by an endothermic peak on the DTA dependence. This mass loss is due to evaporation of water. When the temperature increased to $\mathrm{T}_{2}=140{ }^{\circ} \mathrm{C}$, destruction began to occur in the sample (Figure 5).

During heating, in the region $\mathrm{T}_{1}=108^{\circ} \mathrm{C}$, the mass was lost at $\Delta \mathrm{m}=14.5 \%$, which was accompanied by an endothermic peak at the DTA. With a temperature rise up to $\mathrm{T}_{2}=131{ }^{\circ} \mathrm{C}$, a degradation occurs in the sample (Figure 6).

When the candied fruit was heated in the $\mathrm{T}_{1}=109^{\circ} \mathrm{C}$ area, there was a loss of mass by $\Delta \mathrm{m}=14.8 \%$. with an endothermic peak on the DTA dependence. As the temperature rises to $\mathrm{T}_{2}=125^{\circ} \mathrm{C}$, destruction began to occur in the sample (Figure 7).

The table below shows the samples and the moisture content of the finished samples. 


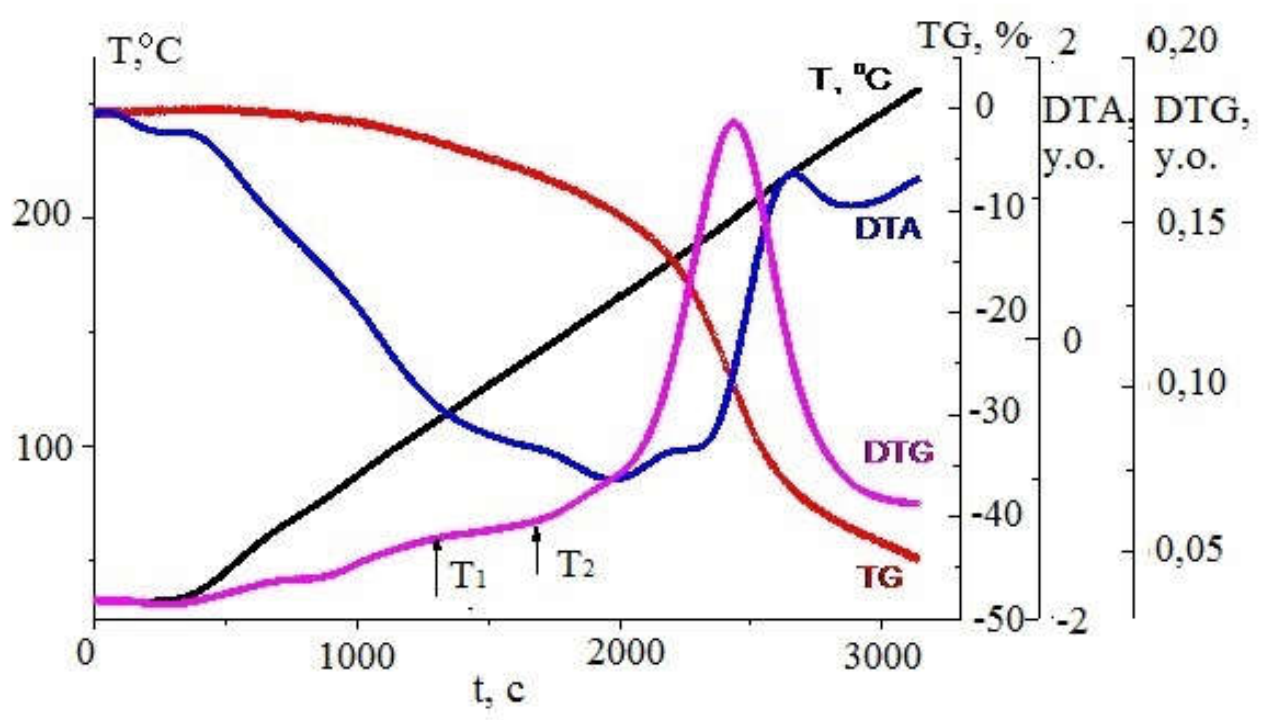

Figure 5. Derivatogram dried apples «Golden Delicious»:

T - time dependencies of temperature; TG - inward masi apple; DTA - differential-term analysis; DTG - derivative of the mass loss

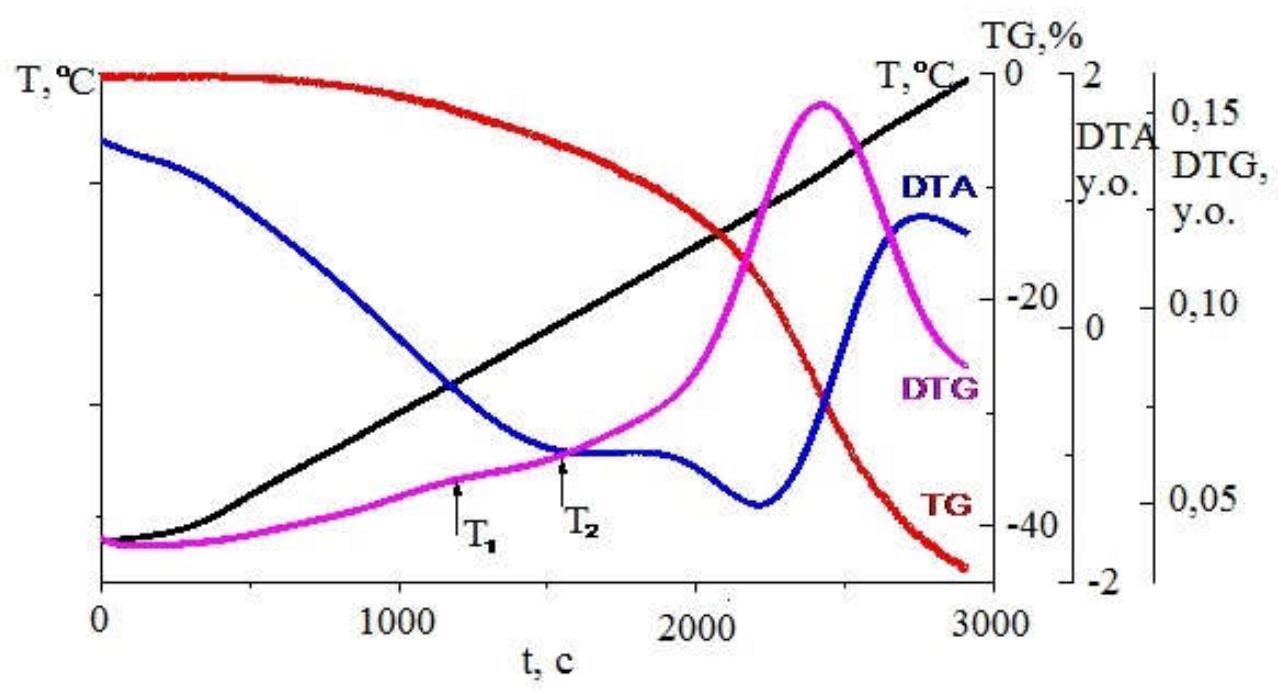

Figure 6. Derivatogram for snack «Golden Delicious»:

T - time dependencies of temperature; TG - inward masi apple; DTA - differential-term analysis; DTG - derivative of the mass loss 


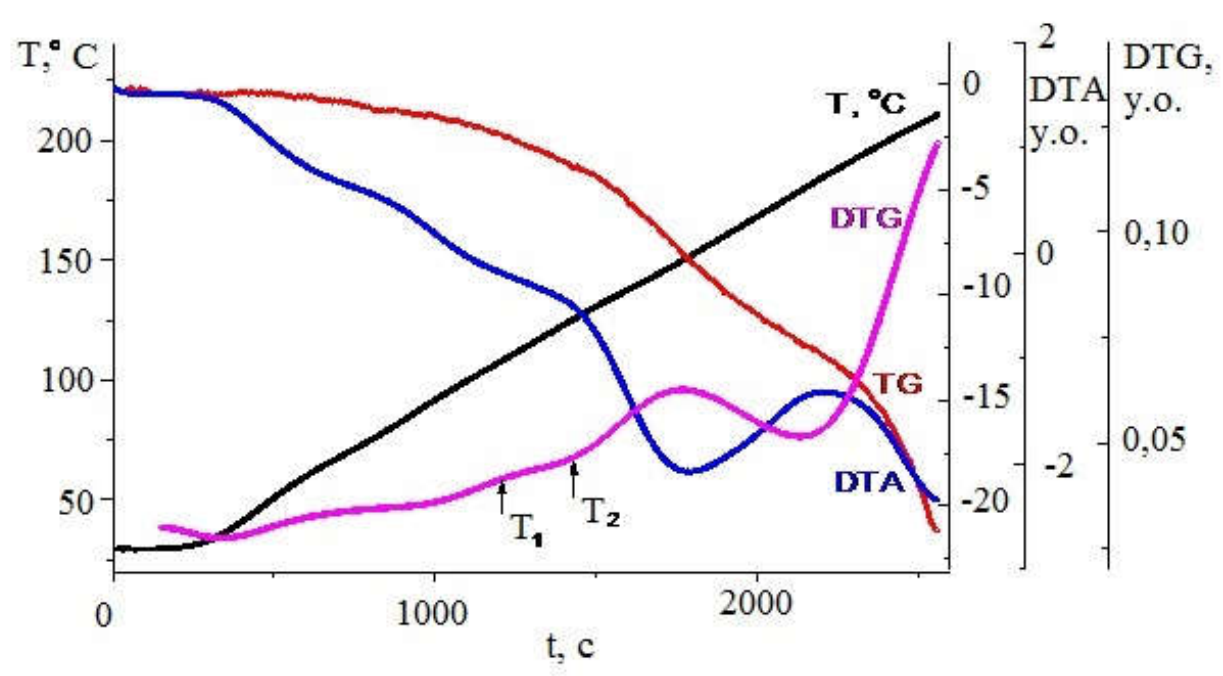

Figure 7. Derivatogram for candied fruits «Golden Delicious»:

T - time dependencies of temperature; TG - inward masi apple;

DTA - differential-term analysis; DTG - derivative of the mass loss

Moisture content of the studied samples

Table 3

\begin{tabular}{|c|c|c|c|}
\hline The moisture content & \multicolumn{3}{|c|}{ Product } \\
\cline { 2 - 4 } of the products & Dried apples & Snack & Candied fruits \\
\hline$\%$ & 13.0 & 14.5 & 14.8 \\
\hline
\end{tabular}

As it was already noted, mass loss by samples is accompanied by the appearance of endothermic peaks on the temperature dependences of the DTA (Figure 5, 6, 7). The endothermic peak is associated with the phase transition of the first stem - evaporation. That is, in the samples during heating there was evaporation of moisture in the region of $110^{\circ} \mathrm{C}$. An increase in the temperature of evaporation (in comparison with the boiling point of water) can be explained by the fact that the water in the samples was in the bound state (in the hydrate shell).

Using the described method, the activation energy (E) and the pre-exponential factor $\left(\mathrm{k}_{0}\right)$ were calculated, which are given in Table 4.

Table 4

Activation energy (E) and the preexposure factor $\left(k_{0}\right)$ for the samples

\begin{tabular}{|c|c|c|c|}
\hline Product & Dried apples & Snack & Candied fruits \\
\hline $\mathrm{k}_{0}$ & 55 & 61 & 70 \\
\hline $\mathrm{E} \mathrm{kJ} / \mathrm{mol}$ & 186 & 203 & 236 \\
\hline
\end{tabular}

Table 4 shows, that the higher the moisture content in the product, the higher the activation energy. 


\section{Explanation of the results}

Scientists of the world [1] elected a winter variety of apples «Idared» as an experimental sample, which is distinguished by a large fruit size, a light flesh and an acceptable sweet-sour taste with a sugar-acid indicator of more than 4.

Based on the results of our own research, «Golden Delicious» apples were selected as raw materials for the production of apple snack due to excellent performance and low peroxidase activity.

Pre-processing of «Idared» apples [1] was to clean, cut and immerse the raw material in $40 \%$ glucose syrup at a temperature of $18-22$, but a long osmotic treatment leads to an increase in the manufacturing cycle of this product, a short-term - less than 15-20 minutes gives the desired result, that is, does not provide the sweet taste of the product. The concentration of sugar in these snack is not uniform - in the peripheral zones, its concentration is higher than in the middle. The process of internal diffusion does not reach the state of equilibrium or its complete absence in the inner layers. This can significantly affect the quality of the finished product, because during convective drying at a temperature of 105-110, as the authors claim, Mayer reactions can form, which negatively affect both organoleptics (aroma, taste) and physical-chemistry product (reducing the content of organic acids and vitamin C). The final moisture content of snake is $6-8 \%$. The low moisture content in the product gives a specific sound of a crunch when breaking, therefore the authors call this product chips.

Analyzing the results of research by world scientists, technology was developed taking into account certain shortcomings. Preparation of apple raw materials is focused on blanching in $30 \%$ sugar syrup with the addition of citric acid in the amount of $0.5-1 \%$ and ascorbic acid $0.05-0.1 \%$. To avoid cooking the fruit after blanching, the apple particles are cooled in a similar syrup with a temperature of $18-20{ }^{\circ} \mathrm{C}$ to room temperature. Drying is carried out under softened conditions at a coolant temperature of $40-60{ }^{\circ} \mathrm{C}$ to a product moisture content of not more than $15 \%$.

The world presents a large part of the scientific work on drying food products by the convective method $[16,17]$; thermoraditional; microwave and temperature effects on the quality of the finished product; by the sublimation method [2], but together with the advantages of the methods there is a significant drawback - energy consumption, therefore, the creation of an energy-efficient method of drying or cheapening of already existing dryers remains urgent. There are convection units with a heat pump [18], which allow you to save energy without negative consequences for the dried products. However, it is necessary to look for new solutions and create progressive dryers.

The developed convectiv-thermoradiation method of drying is energy efficient compared to convective by $25-30 \%$. At the same time, the final inactivation of enzymes is provided, it is positively noted on the quality of the finished product, in particular on the visual appearance, which is one of the main criteria for consumer choice of food products.

The results of research have a scientific novelty and may be of interest for the industrialization of technology in production. One of the urgent tasks of technologists will always be improving the quality of the finished product. The obtained samples of dried apples and candied fruits, made by usage of the combined method of drying, have high organoleptic and physico-chemical indicators and can be realized in commercial networks: dried apples for the production of compotes; candied fruit - for the industrial production of cakes, muffins, cakes as fillers. Apple snacks are a quick snack without the use of artificial additives, but enriched with vitamins using ascorbic acid. 
The advantages of the presented studies include the ease of operation of the pilot plant and the possibility of changing the drying parameters in a wide range: temperature, air velocity in the chamber, voltage of heating elements, distances from thermal radiation generators to the product, air recirculation, unit load on the installation, the possibility of fixing power consumption any moment of research. If necessary, the dryer can be transferred to one of the drying methods, for example, when candied fruits are blown off, only convection is used to remove excess moisture after washing the fruit.

The disadvantage of the installation is that it is periodic in action and requires additional time to load and unload a portion of the product that goes into drying.

The presented studies have a scientific novelty, and pretreatment of apple raw materials in the manufacture of apple snacks provides high organoleptic characteristics (attractive light color typical of the raw materials used; rich apple flavor; pleasant sweet-sour taste), physical and chemical indicators (high content of vitamin C). In the future, these studies will be continued and focused on the packaging of these products and physical and chemical changes during storage.

\section{Conclusions}

1. Blanching for the production of dried apples was carried out according to the actual technical instructions, and blanching of raw materials for snack production was in the recommended sugar syrup, based on previous studies, with concentration of $30 \%$. The semi-finished product was also cooled in $30 \%$ sugar syrup with the addition of citric and ascorbic acid. Preparation in the production of candied fruit was the manufacture of jam in three stages with its periodic cooling to ambient temperature, followed by boiling

2. The process of combined convection-thermoraditional drying is investigated and drying curves and drying speed curves of dried apples, snack and candied fruits are presented. Approximation equations are derived for the first and second drying periods for all products from apple.

3. Experimentally determined the amount of electricity consumed spent on drying products from apple - in the production of dried apple costs amounted to $5.9 \mathrm{~kW} / \mathrm{kg}$ of raw materials $(1.93 \mathrm{MJ} / \mathrm{kg}$ of evaporated moisture $)$ in the production of snack -7.55 $\mathrm{kW} / \mathrm{kg}$ of raw materials ( $1.99 \mathrm{MJ} / \mathrm{kg}$ of evaporated moisture) in the production of candied fruits $-19.8 \mathrm{~kW} / \mathrm{kg}$ of raw materials (26.0 MJ/kg of evaporated moisture).

4. A differential thermal analysis of dry product samples has been performed and it has been established that the energy of water activation in candied fruits is higher by 50 $236 \mathrm{~kJ} / \mathrm{mol}$, and in apple snack it is higher by $33-203 \mathrm{~kJ} / \mathrm{mol}$, in comparison with dried apples $(186 \mathrm{~kJ} / \mathrm{mol})$. It is proved that higher energy of activation of moisture removal has samples with high moisture content of macro- and microcapsules; the forms of moisture bonding in the material in each product were identified.

\section{References}

1. Velickova E., Winkelhausen E., Kuzmanova S. (2014), Physical and sensory properties of ready to eat apple chips produced by osmo-convective drying, Journal of Food Science and Technology, 51(12), pp. 3691-3701

2. Hawkes J., Flink J.M. (2013), Osmotic concentration of fruit slices prior to freeze dehydration, Journal of Food Processing and Preservation, 19782(4), p. 265. 


\section{— Processes and Equipment-_}

3. (2009) Effect of different treatments on the preference of apple cubes dehydrated by a combined process,

Available at: https://www.ncbi.nlm.nih.gov/pubmed/19817634

4. Joshi A.P.K., Rupasinghe H.P.V., Khanizadeh S. (2011) Impact of drying processes on bioactive phenolics, vitamin C and antioxidant capacity of red-fleshed apple slices, Journal of Food Processing and Preservation, 35(4), pp. 453-457.

5. Tavera-Quiroz M., Urriza M., Pinotti A., Bertola N., (2014), Development and Characterization of a Baked Snack from Rings of Green Apples, Food and Bioprocess Technology, 7(8), pp. 2218 2227.

6. Reihaneh N., Parastoo Y., Durance T. (2013), Radiant energy under vacuum (REV) technology: A novel approach for producing probiotic enriched apple snack, Journal of Functional Foods, 5(3), pp. 1049-1056.

7. Malejik I., Dubkovetskyy I., Bandurenko H., Strelchenko L., Levkivska T. (2016), The Use of convective-thermoradiactive method of energy supply in the apple snack technology, SkhidnoYevropeiskyi zhurnal peredovykh tekhnolohii, 6/11(84), pp. 47-52.

8. Guohui Hao, Jianjun Liu, and Zhi Hong (2011), Determination of soluble solids content in apple products by terahertz time-domain spectroscopy, International Symposium on Photoelectronic Detection and Imaging 2011: Terahertz Wave Technologies and Applications, Proc. of SPIE Vol. 8195, 819510, DOI: $10.1117 / 12.900671$

9. Agota Giedrè Raišiené, Artiom Volkov, Virgilijus Skulskis, Rita Vilkè (2018), Representation of agricultural producers' interests: substantiation of the research construct, Ukrainian Food Journal, 7(3), pp. 522-535.

10. (1998), SO 750:1998. Fruit and vegetable products - Determination of titratable acidity, Available at: https://www.iso.org/standard/22569.html.

11. ISO 751:1981. Fruit and vegetable products -- Determination of water-insoluble solids content, Available at: https://www.iso.org/standard/5007.html.

12. ISO 2173:1978. Fruit and vegetable products -- Determination of soluble solids content Refractometric method,

Available at: https://www.iso.org/standard/6970.html.

13. Kertesz Z.I. (1957), Preparation and determination of pectic substances, Methods in Enzymology, 3 , pp. 27-30.

14. ISO 6557-1:1986. Fruits, vegetables and derived products -- Determination of ascorbic acid - Part 1: Reference method, Available at: https://www.iso.org/standard/12956.html.

15. (2017), Influence of Water on the Structure and Dielectric Properties of the Microcrystalline and Nano-Kovalov etal, Nanoscale Research Letters, 12, p. 468, DOI: 10.1186/s11671-017-2231-5.

16. Chua K., Mujumdar A., Chou S., Hawlader M., Ho J. (2000), Heat pump drying of banana, guava and potato pieces: Effect of cyclical variation of air temperature on convective drying kinetics and color change, Drying Technology., 18(5), pp. 907-936.

17. Doymaz İ., (2010), Effect of citric acid and blanching pre-treatments on drying and rehydration of Amasya red apples, Food and Bioproducts Processing, 88(2-3), pp. 124-132.

18. Sunthonvit N., Srzednicki G., Craske J., (2007), Effects of Drying Treatments on the Composition of Volatile Compounds in Dried Nectarines, Drying Technology, 25 (95), pp. 877-881.

19. Dubkovetsky I., Malejik I., Strelchenko L. (2018), Investigation of convective-thermoradiation drying of products from apples in two stages, Proceeding of International Conference "Modern Technologies in the food Industry”, Chisinau, 2018, p. 123.

20. Vadym Pazyuk, Zhanna Petrova, Oleksandr Chepeliuk (2018), Determination of rational modes of pumpkin seeds drying, Ukrainian Food Journal, 7(1), pp. 135-150

21. Galnaitytè, A., Kriščiukaitienè, I., Baležentis, T., Namiotko, V.(2017), Evaluation of Technological, Economic and Social Indicators for Different Farming Practicesin Lithuania, Economics \& Sociology, 10(4), pp. 189-202, DOI: 10.14254/2071-789X.2017/10-4/1.

22. Drobot V.I., Arsenieva L.Yu., Bilyk O.A., Dotsenko V.F. (2006), Laboratornyi praktykum z tekhnolohii khlibopekarskohota makaronnoho vyrobnytstva, Kyiv. 